\title{
Studi Penentuan Prioritas Rehabilitasi Berdasarkan Efisiensi Saluran Pada Saluran Primer Air Manna I Kabupaten Lahat
}

\author{
Imanuel T. Ranteta'dung ${ }^{1 *}$, M. Janu Ismoyo ${ }^{1}$, Tri Budi Prayogo ${ }^{1}$ \\ ${ }^{1}$ Jurusan Teknik Pengairan, Fakultas Teknik, Universitas Brawijaya, \\ Jalan MT. Haryono No. 167, Malang, 65145, INDONESIA \\ *Korespondensi Email: imanuelthree31@gmail.com
}

\begin{abstract}
The Air Manna I Irrigation Area, located in Lahat Regency, is able to irrigate 331 ha of rice fields. The problem that occurs in the Primary Air Manna I canal, there is some damage to the irrigation assets in the canal so that it can reduce the efficiency and performance of the canall. For this reason, it is necessary to calculate canal efficiency and identify canal damage in order to determine priority for canal rehabilitation. This research aims to determine the value of canal efficiency, canal performance, priority canal rehabilitation, and canal rehabilitation costs by presenting in a map the condition of the primary canal Air Manna I using the Google Earth application. The method used is calculating the efficiency value of each canall segment, based on the calculation of flow velocity, passenger area and canall discharge to determine priority for channel rehabilitation. The results of this study: The priority for canal rehabilitation at rank 1 is section III (BAM.3-BAM.4a) with an efficiency value of $59 \%$ and canal performance of $35 \%$ and requires a fee of Rp.421,520,000.00. The priority for canal rehabilitation for rank 2 is section I (BAM.1-BAM.2) with an efficiency value of $78 \%$ and a canal performance of $55 \%$ and requires a fee of Rp.141,930,000.00. The priority for canall rehabilitation at rank 3 is section II (BAM.2-BAM.3) with an efficiency value of $81 \%$ and a canal performance of $60 \%$ and requires a fee of Rp. 128,270,000.00
\end{abstract}

Keywords: canal condition, cost, efficiency, rehabilitation priorities

Abstrak: Daerah Irigasi Air Manna I yang terletak di Kabupaten Lahat, mampu mengairi 331ha lahan persawahan. Kerusakan di beberapa titik pada saluran Primer Air Manna 1 merupakan sebuah permasalahann yang dapat menurunkan0nilai efisiensi dan kinerja saluran. Untuk itu diperlukan adanya perhitunagn efisiensi saluran dan identifikasi kerusakan saluran agar dapat menentukan prioritas rehabilitasi saluran. Penelitian ini bertujuan untuk mengetahui nilai efisiensi saluran, kinerja saluran, prioritas rehabilitasi saluran, dan biaya rehabilitasi saluran dengan menyajikan dalam peta kondisi saluran primer Air Manna I menggunakan aplikasi Google Earth. Metode yang digunakan adalah menghitung nilai efisiensi dari setiap ruas saluran, berdasarkan perhitungan kecepatan aliran, luas penumpang dan debit saluran untuk menentukan prioritas rehabilitasi saluran. Hasil dari penelitian ini adalah: Prioritas rehabilitasi saluran peringkat 1 adalah ruas III (BAM.3-BAM.4a) 
dengan nilai efisiensi sebesar 59\% dan kinerja saluran 35\% serta membutuhkan biaya sebesar Rp.421.520.000,00. Prioritas rehabilitasi saluran peringkat 2 adalah ruas I (BAM.1-BAM.2) dengan nilai efisiensi sebesar 78\% dan kinerja saluran 55\% serta membutuhkan biaya sebesar Rp.141.930.000,00. Prioritas rehabilitasi saluran peringkat 3 adalah ruas II (BAM.2-BAM.3) dengan nilai efisiensi sebesar $81 \%$ dan kinerja saluran 60\% serta membutuhkan biaya sebesar Rp.128.270.000,00.

Kata kunci: biaya, efisiensi, kinerja saluran, prioritas rehabilitasi,

\section{Pendahuluan}

Irigasi merupakan salah satu sarana pemanfaatan sumber daya air yang berfungsi sebagai penyedia, pengatur dan penyalur air untuk menunjang lahan pertanian [1].

Sistem pengelolaan irigasi yang efisien dan efektif sangat mempengaruhi hasil produksi pertanian yang maksimal dalam rangka ketahanan pangan nasional.Kebutuhan air irigasi dapat tercukupi dengan baik apabila kinerja jaringan irigasi baik. Salah satu kinerja jaringan irigasi dapat dilihat dari nilai efisiensi irigasi. Kondisi aset irigasi yang buruk akan menyebabkan penurunan efisiensi irigasi. Meskipun jumlah air tersedia cukup, namun apabila konsistensi efisiensi distribusi air tidak terjaga, maka dapat menyebabkan air tidak dapat mencukupi seluruh areal yang direncanakan.

Daerah Irigasi (DI) Kewenangan Provinsi di Kabupaten Lahat terdapat 8 Daerah Irigasi (DI) [2]. Rata-rata Indeks Kinerja Sistem Irigasi (IKSI) di Kabupaten Lahat, mendapat bobot penilaian 40.65 yang berarti kondisi rusak berat dan perlu pemeliharan berkala yang bersifat perbaikan besar atau pergantian.

Daerah Irigasi (DI) Air Manna I di Kecamatan Tanjung Sakti Pumi, Kabupaten Lahat, Sumatera Selatan area lahan persawahannya memperoleh suplai air dari Sungai Air Manna. Kondisi Saluran Primer Air Manna I tahun 2019 60\% dalam kondisi baik dan 40\% kondisi buruk.

Kerusakan di beberapa titik pada Saluran Primer Air Manna 1 merupakan sebuah permasalahan yang dapat menutunkan nilai0efisiensi0dan0kinerja0saluran. Rehabilitasi saluran irigasi merupakan langkah penting yang wajib dilakukan oleh pemerintah. Pemerintah melalui Anggaran Pendapatan dan Belanja Negara (APBN) menyediakan Dana Alokasi Khusus (DAK) yang dapat dimanfaatkan untuk kegiatan rehabilitasi dengan tujuan untuk meningkatkan fungsi dan kondisi fisik aset irigasi. Alokasi DAK yang terbatas mengakibatkan pelaksanaan rehabilitasi harus dilakukan secara bertahap tetapi berkelanjutan, sehingga diperlukan penentuan prioritas rehabilitasi.

\section{Bahan dan Metode}

\subsection{Bahan}

\section{A. Lokasi Studi}

Studi ini bertempat di saluran primer Air Manna I, Kabupaten Lahat, Provinsi Sumatera Selatan. Terletak pada 40 09.19' LS - 40 10' LS dan 1030 03.22' BT - 1030 05' BT. Saluran primer Air Manna I memiliki Panjang 2.022 meter. 


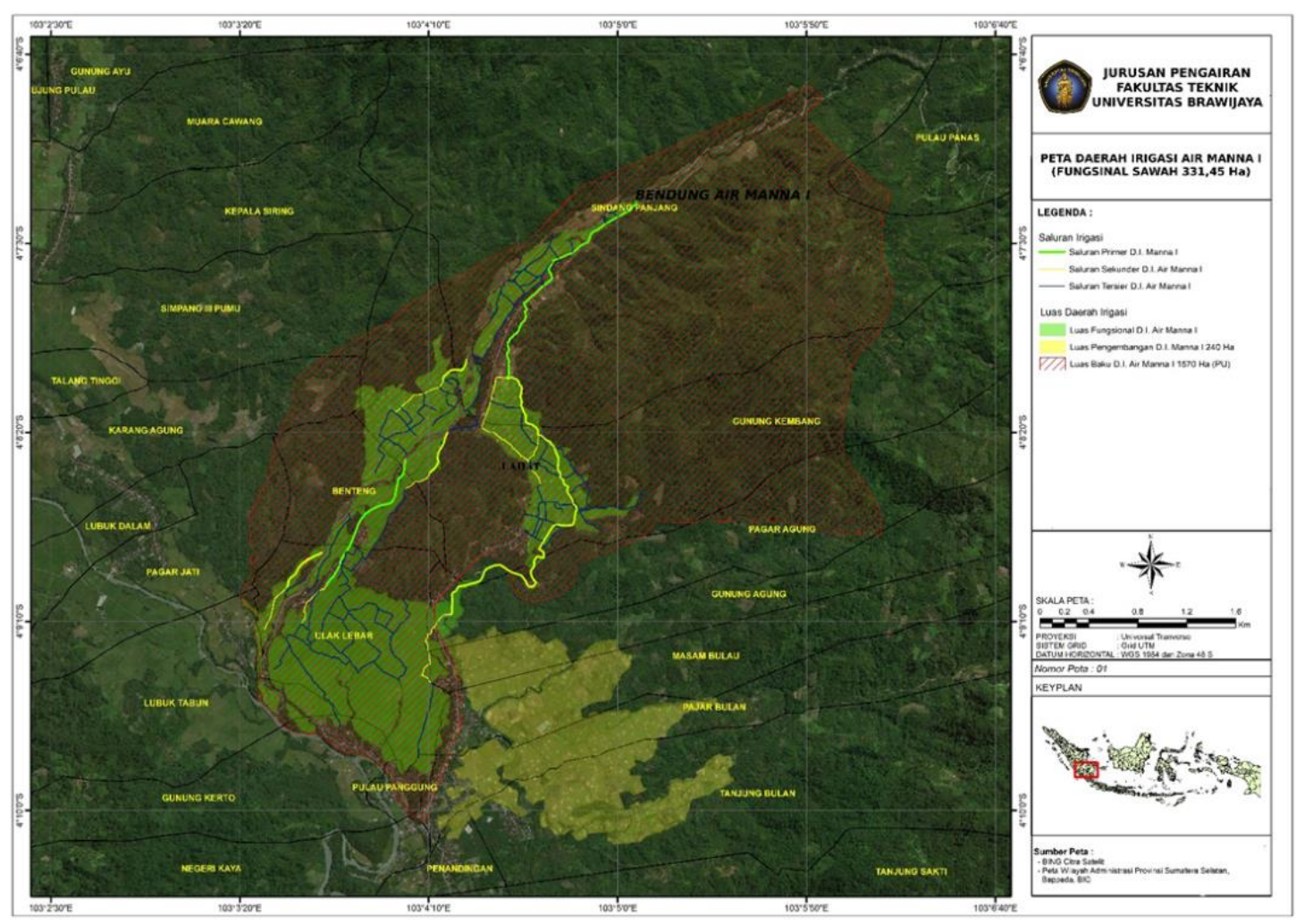

Gambar 1: Peta Daerah Irigasi Air Manna I

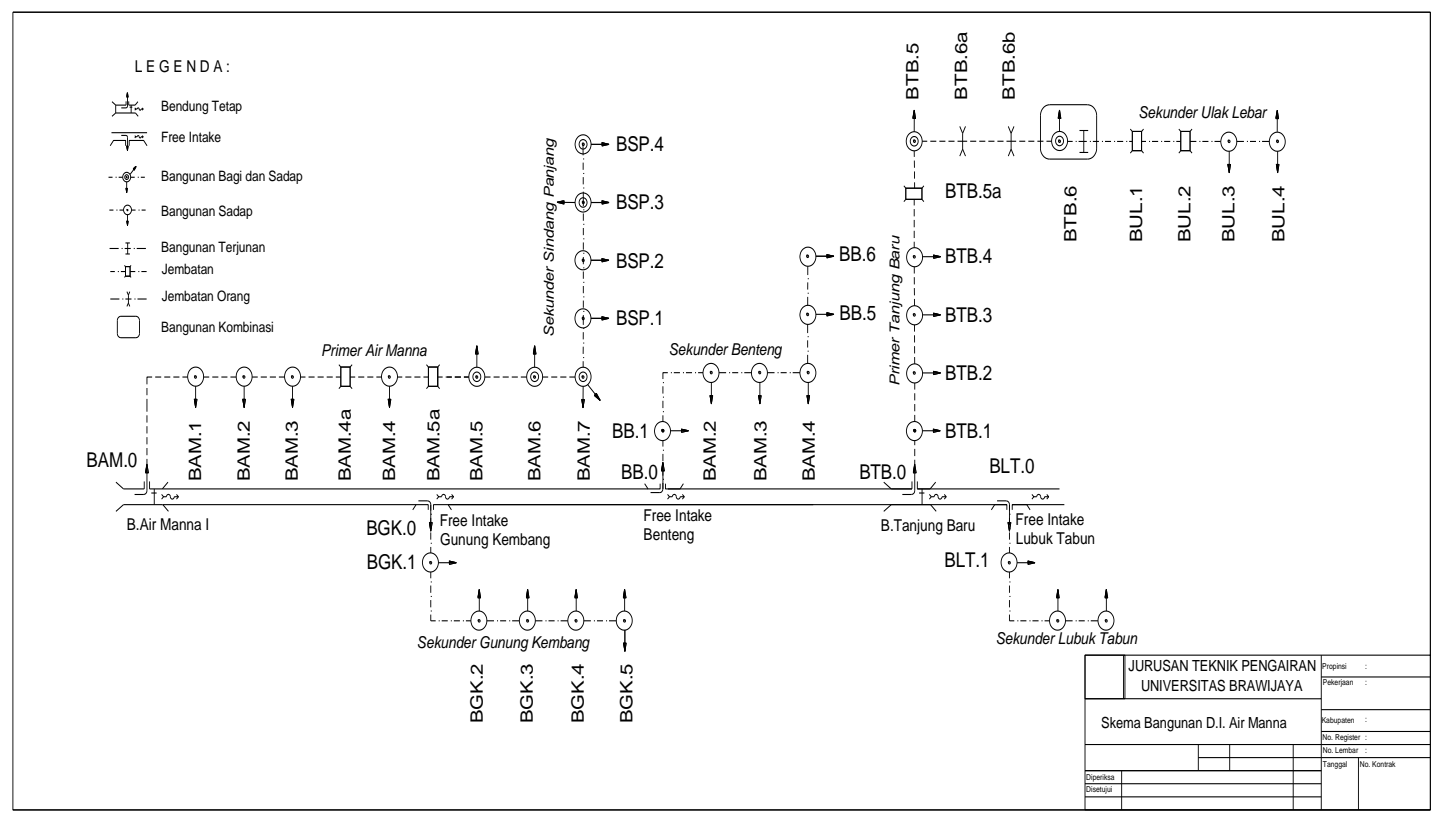

\section{Gambar 2: Peta Skema Jaringan D.I. Air Manna I}

\section{B. Data - Data Penelitian}

Terdapat data primer dan data sekunder yang diutuhkan dalam studi ini. Data primer yang dibutuhkan antara lain : dokumentasi asset irigasi, kecepatan aliran air, debit aliran, dan luas penampang basah saluran. Data sekunder yang dibutuhkan dalam penelitian ini natara lain : Skema bangunan irigasi dan Harga Satuan Pekerjaan (HSP) Kabupaten Lahat 2019. 


\subsection{Metode}

A. Langkah - Langkah Pengerjaan Studi

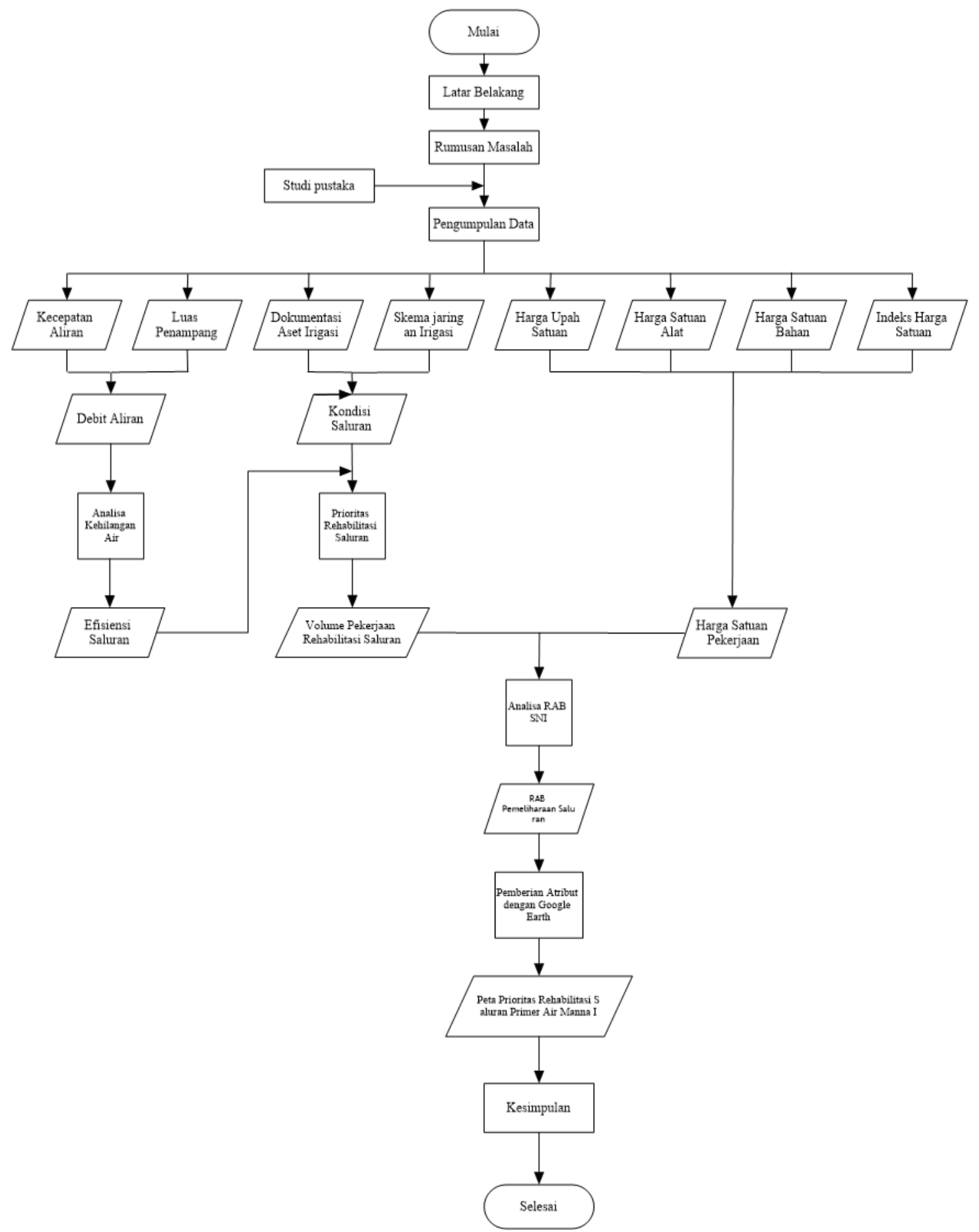

\section{Gambar 3: Diagram Alir Penellitian}

B. Faktor - faktor Penentuan Patok

Faktor-faktor dalam penentuan patok pada penelitian ini adalah: hulu dan hilir bangunan bagi sadap, tidak pada terjunan dan belokan, tidak pada bangunan ukur, pada aliran yang tenang, tidak dibawah pintu air, kondisi tambahan ketika terdapat kerusakan parah pada saluran. 
Maka melihat dari skema jaringan saluran primer Air Manna I, maka terdapat 15 ruas yang menjadi titik pengukuran kecepatan aliran.

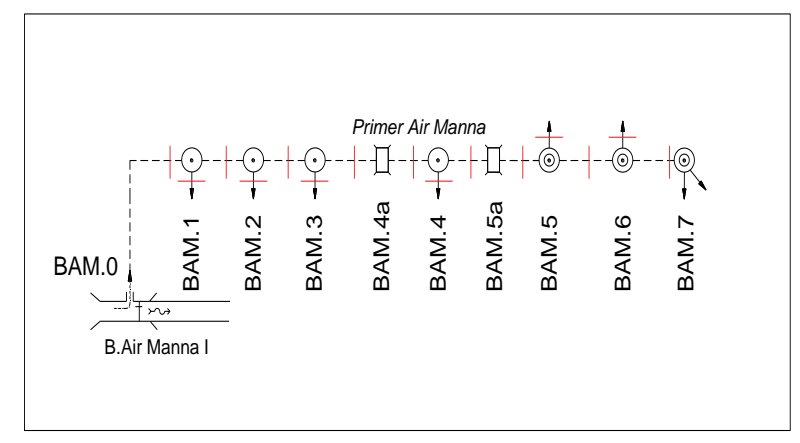

Gambar 4: Lokasi Titik Pengukuran

\subsection{Persamaan}

\section{A. Kecepatan Aliran}

Current meter adalah alat yang dapat mengukur kecepatan arus titik dalam satu penampang aliran tertentu [3]. Pada current meter tipe C2 "10.150" ditetapkan koofisien dari alat dengan rumus:

$$
\begin{array}{ll}
\mathrm{n}<2,20 \mathrm{~V}=0,0160 \mathrm{n}+0,017 & \text { Pers. } 1 \\
\mathrm{n}>2,20 \mathrm{~V}=0,0560 \mathrm{n}+0,028 & \text { Pers. } 2 \\
\mathrm{n}<6,80 \mathrm{~V}=0,0560 \mathrm{n}+0,028 & \text { Pers. } 3 \\
\mathrm{n}>6,80 \mathrm{~V}=0,0535 \mathrm{n}+0,045 & \text { Pers. } 4
\end{array}
$$

Pengukuran kecepatan aliran menggunakan tiga indicato yaitu kanan, tengah dan kiri untuk melihat pengaruh lining saluran terhadap kecepatan aliran. Untukmenghitung kecepatan rata-rata aliran bidang indicato tegantung kedalaman air dan penempatan baling-baling terhadap muka air. Untuk menentukan kecepatan rata-rata aliran dapat menggunakan rumus pada Tabel 1

Tabel 1: Rumus Kecepatan Rata-rata Aliran dengan Current Meter

\begin{tabular}{ccl}
\hline $\begin{array}{c}\text { Kedalaman } \\
\text { Saluran }\end{array}$ & \multicolumn{1}{c}{$\begin{array}{c}\text { Kedalaman } \\
\text { pengukuran }\end{array}$} & \multicolumn{1}{c}{ Perhitungan kecepatan rata-rata } \\
\hline$(\mathrm{m})$ & \multicolumn{1}{c}{$(\mathrm{m})$} & \multicolumn{1}{c}{$(\mathrm{m} /$ detik $)$} \\
$0-0,3$ & $0,6 \mathrm{~h}$ & $\mathrm{~V}: \mathrm{V} 0,6$ \\
$0,31-3$ & $0,2 \mathrm{~h}$ dan $0,8 \mathrm{~h}$ & $\mathrm{~V}: 0,5(\mathrm{~V} 0,2+\mathrm{V} 0,8)$ \\
$3,1-6$ & $0,2 \mathrm{~h}, 0,6 \mathrm{~h}$ dan $0,8 \mathrm{~h}$ & $\mathrm{~V}: 0,25(\mathrm{~V} 0,2+2 \mathrm{~V} 0,6+\mathrm{V} 0,8)$ \\
\hline
\end{tabular}

\section{B. Debit Aliran}

Jumlah zat cair yang mengalir melalui tampang lintang aliran tiap satu satuan waktu disebut debit aliran (Q). Debit aliran diukur dalam volume zat cair tiap satuan waktu, sehingga satuannya adalah meter kubik per detik (m3/detik) atau sebuah satuan yang lain (liter/detik, liter/menit, dsb) [4]. Rumus yang digunakan adalah:

$$
\mathrm{Q}=\mathrm{A} \times \mathrm{V} \quad \text { Pers. } 5
$$

dimana, Q : Debit aliran (m3/detik), A : luas penampang basah $\left(\mathrm{m}^{2}\right), \mathrm{V}$ : kecepatan aliran (m/detik).

C. Perhitungan Kehilangan Debit

Kehilangan debit pada tiap ruas pengukuran debit masuk (inflow)-debit keluar (outflow) diperhitungkan sebagai selisih antara debit masuk dan debit keluar [5]. 


$$
\mathrm{hn}=\mathrm{In}-\mathrm{On} \quad \text { Pers. } 6
$$

dimana, hn : kehilagan air pada ruas pengukuran saluran ke n (lt/ detk), In : debit masuk ruas pengukuran ke n (lt/detik), On : debit keluar ruas pengkuran ke n (lt/detik),

\section{Efisiensi Pengaliran}

Disebut juga efisiensi penyaluran air, yaitu efisiensi di saluran utama yakni primer dan sekunder dari bendung sampai ke sadap tersier. Pada perhitungannya digunakan persamaan [6] :

$$
\mathrm{EPNG}=\frac{A s a}{A d b} \times 100 \% \quad \text { Pers. } 7
$$

dimana, EPNG : efisiensi pengaliran (\%), Asa : jumlah air yang sampai di areal irigasi, Abd : jumlah air yang diambil dari bangunan sadap.

E. Penilaian Kondisi Saluran

Tingkatan penilaian kondisi dan fungsional disajikan dalam Tabel 2 dan Tabel 3 [7].

\begin{tabular}{|c|c|c|}
\hline Kriteria & & Kondisi Fisik \\
\hline Baik & 1 & Bentuk fisik bangunan terlihat utuh tidak ada kerusakan \\
\hline \multirow{4}{*}{$\begin{array}{l}\text { Tingkat } \\
\text { kerusakan } \\
<10 \%\end{array}$} & 2 & Pintu tidak ada yang bocor \\
\hline & 3 & Mistar ukur terlihat jelas \\
\hline & 4 & Tidak ada gerusan pada lantai hilir bangunan \\
\hline & 5 & Terlihat agak kotor (sampah/ tanaman bersemak dll) \\
\hline Rusak Ringan & 1 & Bentuk fisik bangunan tampak ada perubahan \\
\hline \multirow{6}{*}{$\begin{array}{l}\text { Tingkat } \\
\text { kerusakan } \\
10-20 \%\end{array}$} & 2 & Plesteran/ siaran ada beberapa yang mengelupas \\
\hline & 3 & Terlihat retakan rambut tidak struktur \\
\hline & 4 & Pintu ada bocoran kecil \\
\hline & 5 & Operasi pintu berat kurang pelumas/berkarat \\
\hline & 6 & Mistar ukur hilang sebagian \\
\hline & 7 & Ada gerusan kecil lantai hilit bangunan \\
\hline \multirow[t]{3}{*}{ Rusak Sedang } & 1 & Bentuk fisik bangunan tampak ada perubahan \\
\hline & a & Plesteran/ siaran 197ndicato mengelupas \\
\hline & b & Terlihat retakan struktur pecah \\
\hline \multirow{5}{*}{$\begin{array}{l}\text { Tingkat } \\
\text { kerusakan } \\
21-40 \%\end{array}$} & 2 & Pintu ada bocoran cukup besar \\
\hline & 3 & Komponen alat pemutar hilang \\
\hline & 4 & Operasi pintu berat kurang pelumas/ berkarat/macet \\
\hline & 5 & Mistar ukur hilang sebagian \\
\hline & 6 & $\begin{array}{l}\text { Ada gerusan cukup dalam lantai di hilir bangunan berdampak } \\
\text { kerusakan lantai }\end{array}$ \\
\hline \multirow[t]{4}{*}{ Rusak Berat } & 1 & Bentuk fisik bangunan tampak ada perubahan serius \\
\hline & $\mathrm{a}$ & Terlihat struktur pecah-pecah \\
\hline & b & Plesteran/ siaran 197ndicato besar mengelupas \\
\hline & $\mathrm{c}$ & Stabilitas terganggu \\
\hline Tingkat & 2 & Pintu ada bocor besar \\
\hline kerusakan & 3 & Pintu tidak bisa dioperasikan sama sekali \\
\hline \multirow{3}{*}{$>40 \%$} & 4 & Ulir pintu bengkok/daun pintu rusak keropos \\
\hline & 5 & Mistar ukur hilang \\
\hline & 6 & $\begin{array}{l}\text { Ada gerusan cukup dalam lantai di hilir bangunan berdampak } \\
\text { kerusakan lantai }\end{array}$ \\
\hline
\end{tabular}

Tabel 2: Penilaian Kondisi Fisik Saluran 
Tabel 3: Penilaian Kondisi Fisik Saluran

\begin{tabular}{cll}
\hline Kriteria & \multicolumn{1}{c}{ Kondisi Fungsional } \\
\hline \multirow{4}{*}{ Baik } & 1 & Pintu air dapat dioperasikan sesuai prosedur \\
& 2 & Dapat mengalirkan debit air rencana \\
& 3 & Bangunan ukur dapat mengukur dengan baik \\
& 4 & Bangunan dapat digunakan dengan baik \\
\hline \multirow{4}{*}{ Kurang } & 1 & Pintu air dapat dioperasikan sesuai prosedur \\
& 2 & Dapat mengalirkan debit air rencana \\
& 3 & Bangunan ukur kurang dapat mengukur dengan baik \\
& 4 & Bangunan dapat digunakan dengan baik \\
\hline \multirow{4}{*}{ Buruk } & 1 & Pintu air tidak dapat dioperasikan sesuai prosedur \\
& 2 & Kurang dapat mengalirkan debit rencana \\
& 3 & Bangunan ukur tidak dapat mengukur dengan baik \\
& 4 & Bangunan kurang dapat digunakan dengan baik \\
\hline \multirow{3}{*}{ Tidak } & 1 & Pintu air tidak dapat dioperasikan sesuai prosedur \\
berfungsi & 2 & Tidak dapat mengalirkan debit rencana \\
& 3 & Bangunan ukur tidak dapat digunakan untuk mengukur \\
& 4 & Bangunan tidak dapat digunakan dengan baik \\
\hline
\end{tabular}

Penilaian kondisi saluran pembawa dilakukan dengan menghitung kondisi saluran pembawa dan kondisi bangunan pada saluran pembawa dengan metode perhitungan sebagai berikut :

$$
\text { Ksbw }=\frac{K(s b w) 1+\cdots+K(s b w) n}{n} \times 100 \% \quad \text { Pers. } 8
$$

dimana, Ksbw :Kondisi saluran pembawa, K(sbw)1: Kondisi saluran pembawa ke 1, K(sbw)n : Kondisi saluran pembawa ke $\mathrm{n}, \mathrm{n}$ : Jumlah ruas saluran pembawa.

\section{F. Penilaian Kinerja Saluran}

Jenis - jenis pemeliharaan jaringan irigasi meliputi : pengamanan jaringan irigasi, pemeliharaan rutin, pemeliharaan berkala, dan perbaikan darurat [8].

G. Rencana Anggaran Biaya

Perhitungan banyaknya biaya yang diperlukan untuk bahan dan upah, serta biaya-biaya lain yang berhubungan dengan pelaksanaan bangunan atau proyek tersebut adalah yang dimaksud rencana anggaran biaya [9]. Secara umum dapat disimpulkan sebagai berikut [10]:

$$
\mathrm{RAB}=\text { Volume } \mathrm{x} \text { Harga satuan Pekerjaan Pers. } 9
$$

Dimana HSP ialah hasil analisa berdasarkan harga di suatu tempat yang bersangkutan dan berdasarkan lampiran AHS pada Permen PU no 28/PRT/M2016.

\section{Hasil dan Pembahasan}

\subsection{Hasil Perhitungan Kecepatan Aliran}

Kecepatan dari setiap titik dihitung pada ketinggian tertentu berdasarkan tinggi air dan dihitung jumlah putaran propeller setiap 10 detik di setiap titik pengukuran yang sudah ditentukan.

Contoh perhitungan BAM.1

$\mathrm{n}$

$$
\begin{aligned}
& =\frac{\text { Jumlah putaran baling-baling }}{\text { waktu }} \\
& =\frac{186}{10}
\end{aligned}
$$




$$
=18,6=19
$$

Perhitungan selanjutnya ditampilkan pada Tabel 4

Tabel 4: Penilaian Kondisi Fisik Saluran

\begin{tabular}{lccccccccc}
\hline Nomenklatur & \multicolumn{8}{c}{ Jumlah Putaran Propeler } \\
\cline { 2 - 9 } & \multicolumn{3}{c}{ Kiri } & \multicolumn{7}{c}{ As } & \multicolumn{5}{c}{ Kanan } \\
& $0.2 \mathrm{~h}$ & $0.6 \mathrm{~h}$ & $0.8 \mathrm{~h}$ & $0.2 \mathrm{~h}$ & $0.6 \mathrm{~h}$ & $0.8 \mathrm{~h}$ & $0.2 \mathrm{~h}$ & $0.6 \mathrm{~h}$ & $0.8 \mathrm{~h}$ \\
\hline BAM.1 & 19 & & 17 & 10 & & 12 & 10 & 20 \\
BAM.1Ka & & & & & 10 & & & \\
BAM.2 & 16 & & 14 & 11 & & 20 & 15 & 15 \\
BAM.2ka & & & & & 6 & & & \\
BAM.3 & 9 & 13 & 9 & & 14 & 13 & 20 \\
BAM.3Ka & & & & & 5 & & & \\
BAM.4a & 7 & 10 & 8 & & 8 & 6 & 20 \\
BAM.4 & 2 & 9 & 4 & & 10 & 4 & 10 \\
BAM.4Ka & & & & & 4 & & & \\
BAM.5a & 3 & 6 & 4 & & 12 & 4 & 12 \\
BAM.5 & 4 & 5 & 3 & & 8 & 5 & 9 \\
BAM.5Ki & & & & & 4 & & & \\
BAM.6 & 4 & 5 & 5 & & 7 & 5 & 9 \\
BAM.6Ki & & & & & 4 & & & \\
BAM.7 & 4 & 7 & 5 & & 6 & 4 & 12 \\
\hline
\end{tabular}

Contoh perhitungan $\underline{\text { BAM.1 }}$

$0,2 \mathrm{~h}$ kiri

$$
\begin{aligned}
\mathrm{n} & =19 \\
\mathrm{v} & =0.0535 \mathrm{n}+0,045 \\
& =0,0535 \times 19+0,045 \\
& =1,062 \mathrm{~m} / \text { detik }
\end{aligned}
$$

$0,8 \mathrm{~h}$ Kiri

\begin{tabular}{|c|c|c|c|c|c|c|c|c|c|}
\hline \multirow[t]{3}{*}{ Nomenklatur } & \multicolumn{9}{|c|}{ Kecepatan } \\
\hline & \multicolumn{3}{|c|}{ Kiri } & \multicolumn{3}{|c|}{ As } & \multicolumn{3}{|c|}{ Kanan } \\
\hline & $0.2 \mathrm{~h}$ & $0.6 \mathrm{~h}$ & $0.8 \mathrm{~h}$ & $0.2 \mathrm{~h}$ & $0.6 \mathrm{~h}$ & $0.8 \mathrm{~h}$ & $0.2 \mathrm{~h}$ & $0.6 \mathrm{~h}$ & $0.8 \mathrm{~h}$ \\
\hline BAM.1 & 1.062 & & 0.955 & 0.580 & & 0.687 & 0.580 & & 1.115 \\
\hline BAM.1Ka & & & & & 0.580 & & & & \\
\hline BAM.2 & 0.901 & & 0.794 & 0.634 & & 1.115 & 0.848 & & 0.848 \\
\hline BAM.2ka & & & & & 0.364 & & & & \\
\hline BAM.3 & 0.527 & & 0.741 & 0.527 & & 0.794 & 0.741 & & 1.115 \\
\hline BАM.3Ка & & & & & 0.313 & & & & \\
\hline BAM.4a & 0.42 & & 0.58 & 0.473 & & 0.473 & 0.364 & & 0.58 \\
\hline BAM.4 & 0.049 & & 0.5265 & 0.252 & & 0.58 & 0.252 & & 0.58 \\
\hline
\end{tabular}

$$
\begin{aligned}
\mathrm{n} & =17 \\
\mathrm{v} & =0.0535 \mathrm{n}+0,045 \\
& =0,0535 \times 17+0,045 \\
& =0,995 \mathrm{~m} / \text { detik }
\end{aligned}
$$

dan begitu juga perhitungan di 0,2h dan 0,8h As dan Kanan. Perhitungan selanjutkan ditampilkan pada Tabel 5.

Tabel 5: Kecepatan Tiap Titik Per Section 


\begin{tabular}{llllllll}
\hline BAM.4Ka & & & & 0.252 & & & \\
BAM.5a & 0.196 & 0.364 & 0.252 & & 0.687 & 0.252 & 0.687 \\
$\begin{array}{l}\text { BAM.5 } \\
\text { BAM.5Ki }\end{array}$ & 0.252 & 0.308 & 0.196 & & 0.473 & 0.308 & 0.527 \\
$\begin{array}{l}\text { BAM.6 } \\
\text { BAM.6Ki }\end{array}$ & 0.252 & 0.308 & 0.308 & & 0.42 & 0.308 & 0.527 \\
BAM.7 & 0.252 & 0.4195 & 0.308 & & 0.364 & 0.252 & 0.687 \\
\hline
\end{tabular}

Setelah mengetahui kecepatan tiap titik per section, selanjutnya ialah perhitungan kecepatan tiap section yang ditampilkan pada Tabel 6 .

Tabel 6: Kecepatan Tiap Section

\begin{tabular}{lcccc}
\hline \multirow{2}{*}{ Nomenklatur } & \multicolumn{3}{c}{ Kecepatan Rata-Rata } & $\mathrm{V}$ \\
\cline { 2 - 4 } & \multicolumn{3}{c}{$\mathrm{V}$} & \\
\cline { 2 - 4 } & Kiri & As & Kanan & m/dt \\
\hline BAM.1 & 1.008 & 0.634 & 0.848 & 0.830 \\
BAM.1Ka & & 0.580 & & 0.580 \\
BAM.2 & 0.848 & 0.874 & 0.848 & 0.856 \\
BAM.2ka & & 0.364 & & 0.364 \\
BAM.3 & 0.634 & 0.660 & 0.928 & 0.741 \\
BAM.3Ka & & 0.313 & & 0.313 \\
BAM.4a & 0.500 & 0.473 & 0.472 & 0.482 \\
BAM.4 & 0.288 & 0.416 & 0.416 & 0.373 \\
BAM.4Ka & & 0.252 & & 0.252 \\
BAM.5a & 0.280 & 0.470 & 0.470 & 0.406 \\
BAM.5 & 0.280 & 0.335 & 0.417 & 0.344 \\
BAM.5Ki & & 0.252 & & 0.252 \\
BAM.6 & 0.280 & 0.364 & 0.417 & 0.354 \\
BAM.6Ki & & 0.252 & & 0.252 \\
BAM.7 & 0.336 & 0.336 & 0.470 & 0.380 \\
\hline
\end{tabular}

3.2 Perhitungan Luas Penampang

Contoh perhitungan BAM.1:

$$
\begin{aligned}
\mathrm{b} & =3 \mathrm{~m} \\
\mathrm{~h} & =1 \mathrm{~m} \\
\mathrm{~A} & =\mathrm{b} \times \mathrm{h} \\
& =3 \times 1 \\
& =3 \mathrm{~m}^{2}
\end{aligned}
$$

Perhitungan selanjutnya ditampilkan pada Tabel 7.

Tabel 7: Luas Penampang Tiap Section

\begin{tabular}{lccc}
\hline \multirow{2}{*}{ Nomenklatur } & $\mathrm{b}$ & $\mathrm{h}$ & $\mathrm{A}$ \\
\cline { 2 - 4 } & $\mathrm{m}$ & $\mathrm{m}$ & $\mathrm{m}^{\wedge} 2$ \\
\hline BAM.1 & 3.00 & 1.00 & 3.00 \\
BAM.1Ka & 0.35 & 0.25 & 0.09 \\
BAM.2 & 3.00 & 0.75 & 2.25 \\
BAM.2ka & 0.50 & 0.25 & 0.13 \\
\hline
\end{tabular}




\begin{tabular}{llll}
\hline BAM.3 & 3.00 & 0.70 & 2.10 \\
BAM.3Ka & 0.50 & 0.25 & 0.13 \\
BAM.4a & 3.00 & 0.65 & 1.95 \\
BAM.4 & 3.50 & 0.60 & 2.10 \\
BAM.4Ka & 0.50 & 0.25 & 0.13 \\
BAM.5a & 3.50 & 0.50 & 1.75 \\
BAM.5 & 3.50 & 0.50 & 1.75 \\
BAM.5Ki & 1.00 & 0.35 & 0.35 \\
BAM.6 & 3.50 & 0.50 & 1.75 \\
BAM.6Ki & 0.50 & 0.30 & 0.15 \\
BAM.7 & 3.50 & 0.45 & 1.58 \\
\hline
\end{tabular}

3.3 Perhitungan Debit Aliran

Contoh perhitungan BAM.1 :

$$
\begin{aligned}
\mathrm{A} & =3 \mathrm{~m}^{2} \\
\mathrm{~V} & =0,830 \mathrm{~m} / \text { detik } \\
\mathrm{Q} & =\mathrm{A} \times \mathrm{V} \\
& =3 \times 0.830 \\
& =2,5 \mathrm{~m} 3 / \text { detik; } \\
& =2,5 \times 1000 \\
& =2489,0 \mathrm{lt} / \mathrm{detik} 3 / \text { detik }=1000 \mathrm{lt} / \text { detik }
\end{aligned}
$$

Perhitungan selanjutnya ditampilkan pada Tabel 8 .

Tabel 8: Debit Tiap Section

\begin{tabular}{lcccr}
\hline \multirow{2}{*}{ Nomenklatur } & \multicolumn{2}{c}{$\mathrm{A}$} & \multicolumn{2}{c}{$\mathrm{Q}$} \\
\cline { 2 - 5 } & $\mathrm{m}^{\wedge} 2$ & $\mathrm{~m} / \mathrm{det}$ & $\mathrm{m}^{\wedge} 3$ & \multicolumn{1}{c}{$\mathrm{lt} / \mathrm{det}$} \\
\hline BAM.1 & 3.0 & 0.8 & 2.5 & 2489.0 \\
BAM.1Ka & 0.1 & 0.6 & 0.1 & 50.8 \\
BAM.2 & 2.3 & 0.9 & 1.9 & 1926.9 \\
BAM.2ka & 0.1 & 0.4 & 0.0 & 45.5 \\
BAM.3 & 2.1 & 0.7 & 1.6 & 1555.1 \\
BAM.3Ka & 0.1 & 0.3 & 0.0 & 39.1 \\
BAM.4a & 2.0 & 0.5 & 0.9 & 939.1 \\
BAM.4 & 2.1 & 0.4 & 0.8 & 783.8 \\
BAM.4Ka & 0.1 & 0.3 & 0.0 & 31.5 \\
BAM.5a & 1.8 & 0.4 & 0.7 & 711.1 \\
BAM.5 & 1.8 & 0.3 & 0.6 & 601.9 \\
BAM.5Ki & 0.4 & 0.3 & 0.1 & 88.2 \\
BAM.6 & 1.8 & 0.4 & 0.6 & 618.9 \\
BAM.6Ki & 0.2 & 0.3 & 0.0 & 37.8 \\
BAM.7 & 1.6 & 0.4 & 0.6 & 599.2 \\
\hline
\end{tabular}

\subsection{Perhitungan Efisiensi Saluran}

Contoh Perhitungan BAM.1
Q BAM.1 = 2499,0 lt $/$ detik
Q BAM.2 = $=1926,9 \mathrm{lt} / \mathrm{detik}$
Q BAM.1Ka $=50,8$ lt $/$ detik
Qn-1 $=2499,0+50,8$
Q BAM.2Ka $=45,5$ lt $/$ detik
Qn $\quad=1926,9+45,5$

Kehilangan air = Qn-1 - Qn 


$$
\begin{aligned}
& =2539,8-1972,4 \\
& =567,3 \mathrm{lt} / \mathrm{detik} \\
& =\frac{1972,4}{2539,8} \times 100 \% \\
& =78 \%
\end{aligned}
$$

Efisiensi $\quad=\frac{1972,4}{2539,8} \times 100 \%$

Efisiensi rata- rata

$$
\begin{aligned}
& =\frac{78 \%+81 \%+59 \%+87 \%+87 \%+97 \%+96 \%+91}{8} \times 100 \% \\
& =84 \%
\end{aligned}
$$

\begin{tabular}{|c|c|c|c|}
\hline \multirow[t]{2}{*}{ Nomenklatur } & Q & $\begin{array}{l}\text { Kehilangan } \\
\text { Air }\end{array}$ & Efisiensi \\
\hline & $1 \mathrm{t} / \mathrm{det}$ & $1 \mathrm{t} / \mathrm{det}$ & $\%$ \\
\hline BAM.1 + BAM.Ka & 2539.8 & & \\
\hline ВАМ. $2+$ ВАМ. $2 \mathrm{Ka}$ & 1972.4 & 567.3 & $78 \%$ \\
\hline ВАМ.3+ВАМ. $3 \mathrm{Ka}$ & 1594.1 & 378.3 & $81 \%$ \\
\hline BAM.4a & 939.1 & 655.0 & $59 \%$ \\
\hline BAM.4+BAM. $4 \mathrm{Ka}$ & 815.3 & 123.8 & $87 \%$ \\
\hline BAM.5a & 711.1 & 104.2 & $87 \%$ \\
\hline ВАМ.5+ВАМ.5Ki & 690.1 & 21.0 & $97 \%$ \\
\hline BAM.6+BAM.6Ki & 656.7 & 33.3 & $95 \%$ \\
\hline BAM.7 & 599.2 & 57.6 & $91 \%$ \\
\hline Rata - rata & & & $84 \%$ \\
\hline
\end{tabular}

Maka efisiensi saluran primer Air Manna I sebesar $84 \%$. Sehingga nilai rekapitulasi efisiensi saluran primer Air Manna I per ruas dapat dilihat pada Tabel 9 dan grafik efisiensi saluran primer Air Manna I per ruas pada Gambar 5.

Tabel 8: Debit Tiap Section

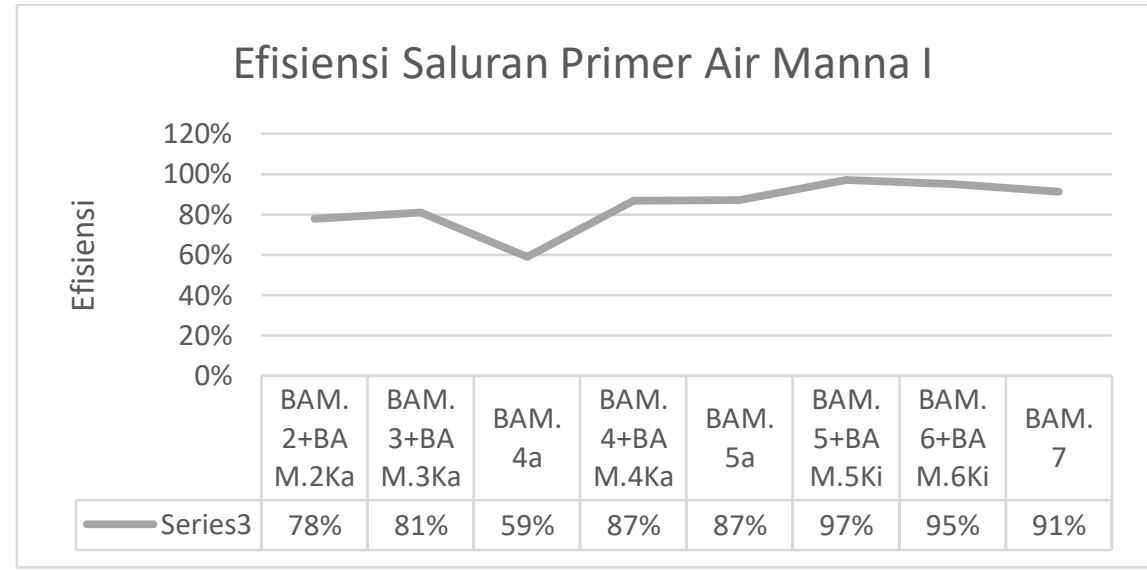

Gambar 5: Grafik Efisiensi Saluran Primer Air Manna I

\subsection{Prioritas Rehabilitasi Saluran}

Untuk mengetahui prioritas rehabilitasi saluran maka perlu mengetahui rekapitulasi nilai efisiensi dan kinerja saluran, nilai rekapitulasi efisiensi dan kinerja saluran disajikan pada Tabel 10 dan grafik efisiensi dan kinerja saluran sekunder Tekung pada Gambar 6. 
Tabel 20: Rekapitulasi Efisiensi dan Kinerja Saluran Primer Air Manna I

\begin{tabular}{lcc}
\hline Nomenklatur & Efisiensi Saluran & Kinerja Saluran \\
\cline { 2 - 3 } & $\%$ & $\%$ \\
\hline BAM.1+BAM.Ka & - & $85 \%$ \\
BAM.2+BAM.2Ka & $78 \%$ & $55 \%$ \\
BAM.3+BAM.3Ka & $81 \%$ & $60 \%$ \\
BAM.4a & $59 \%$ & $35 \%$ \\
BAM.4+BAM.4Ka & $87 \%$ & $70 \%$ \\
BAM.5a & $87 \%$ & $70 \%$ \\
BAM.5+BAM.5Ki & $97 \%$ & $90 \%$ \\
BAM.6+BAM.6Ki & $95 \%$ & $90 \%$ \\
BAM.7 & $91 \%$ & $80 \%$ \\
Rata - rata & $84 \%$ & $71 \%$ \\
\hline
\end{tabular}

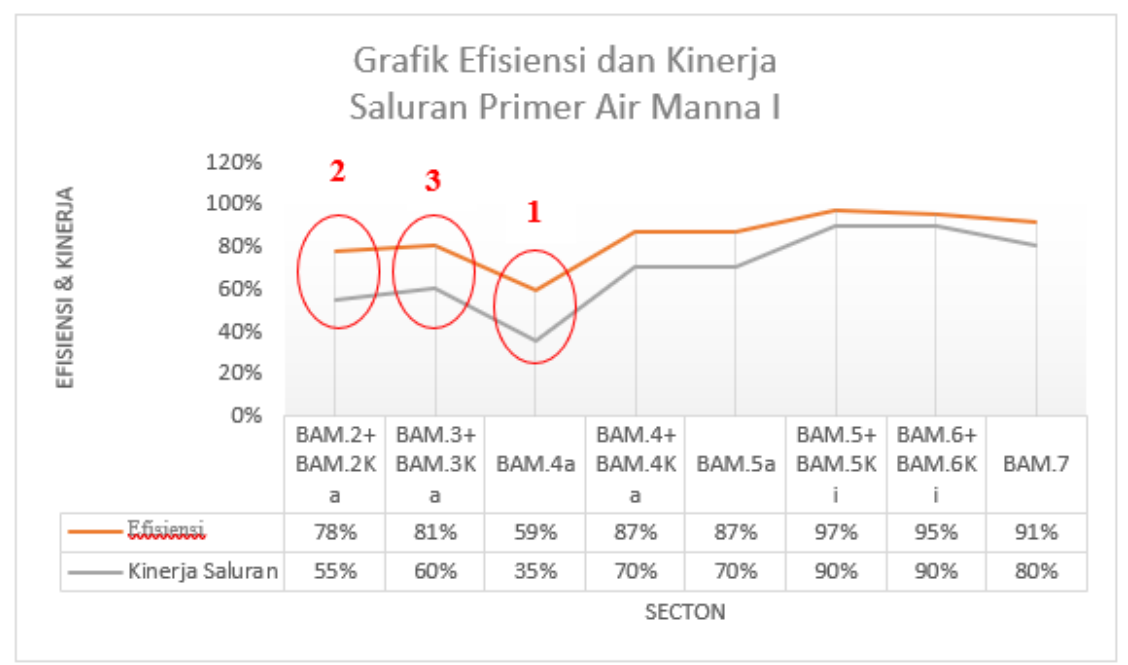

Gambar 6: Grafik Efisiensi dan Kinerja Saluran Primer Air Manna I

Maka dalam menentukan prioritas rehabilitasi saluran, ruas yang memiliki nilai efisiensi terendah akan menjadi prioritas pertama untuk direhabilitasi.

Tabel 31: Prioritas Rehabilitasi Saluran

\begin{tabular}{|c|c|c|c|c|c|}
\hline Peringkat & Nomenklatur & Ruas & $\begin{array}{l}\text { Efisiensi } \\
\text { Saluran } \\
\quad \%\end{array}$ & $\begin{array}{l}\text { Kinerja } \\
\text { Saluran } \\
\quad \%\end{array}$ & Keterangan \\
\hline I & BAM.4a & 3 & $59 \%$ & $35 \%$ & $\begin{array}{l}\text { Dinding saluran } 125 \mathrm{~m} \\
\text { (berupa tanah) }\end{array}$ \\
\hline II & BAM.2+BAM.2Ka & 1 & $78 \%$ & $55 \%$ & $\begin{array}{l}\text { Dinding saluran kiri } 72 \mathrm{~m} \\
\text { (berupa tanah), } 13 \mathrm{~m} \text { (rusak) }\end{array}$ \\
\hline III & BAM.3+BAM.3Ка & 2 & $81 \%$ & $60 \%$ & $\begin{array}{l}\text { Dinding saluran kiri } 22 \mathrm{~m} \\
\text { (berupa tanah), } 14 \mathrm{~m} \text { (rusak) } \\
\text { dan kanan } 39 \mathrm{~m} \text { ( berupa tanah) }\end{array}$ \\
\hline
\end{tabular}

\subsection{Rencana Anggaran Biaya}

RAB pekerjaan dihitung berdasarkan analisa volume perkerjaan serta memperhitungkan AHSP dari harga dasar daerah Kabupaten Lahat tahun 2019. 
Maka dapat diketahui biaya yang dibutuhkan untuk pekerjaan rehabilitasi saluran dari setiap ruas yang sudah di prioritaskan berdaskan nilai efisiensi saluran, sebagai berikut:

Tabel 42: Rekapitulasi Rencana Anggaran Biaya Rehabilitasi Saluran

\begin{tabular}{clcccc}
\hline Peringkat & Nomenklatur & Ruas & $\begin{array}{c}\text { Efisiensi } \\
\text { Saluran } \\
\%\end{array}$ & $\begin{array}{c}\text { Kinerja } \\
\text { Saluran } \\
\%\end{array}$ & $\begin{array}{c}\text { RAB Rehabilitasi } \\
\text { Saluran }\end{array}$ \\
\hline I & BAM.4a & 3 & $59 \%$ & $35 \%$ & Rp 421,520,000.00 \\
II & BAM.2+BAM.2Ka & 1 & $78 \%$ & $55 \%$ & Rp 141,930,000.00 \\
III & BAM.3+BAM.3Ka & 2 & $81 \%$ & $60 \%$ & Rp 128,270,000.00
\end{tabular}

3.7 Tampilan Peta Sekunder Dengan Program Google Earth

Peta Sekunder ini adalah peta yang berisi informasi efisiensi saluran, kinerja saluran, kinerja bangunan pada saluran, usulan perbaikan, peringkat prioritas rehabilitasi, dan RAB rehabilitasi saluran dari setiap ruas dan juga foto bangunan, nama bangunan, nama saluran, BT, LS, kondisi bangunan, kinerja bangunan, usulan perbaikan seperti pada Gambar 7.

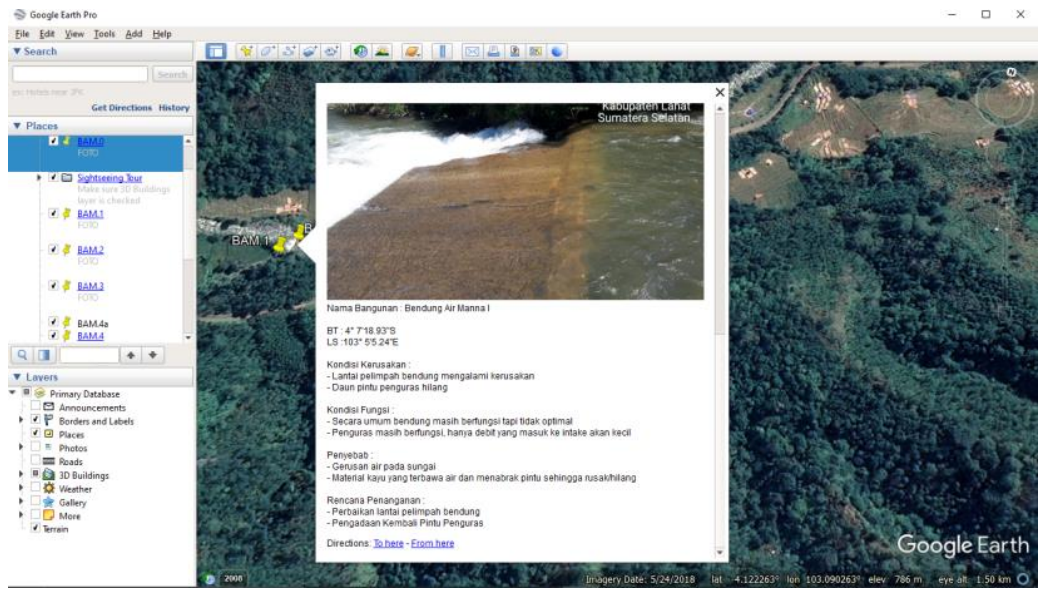

Gambar 7: Tampilan ruas yang sudah diinput deskripsi saluran

Maka tampilan dari seluruh ruas dan bangunan pada saluran primer Air Manna I sebagai berikut:

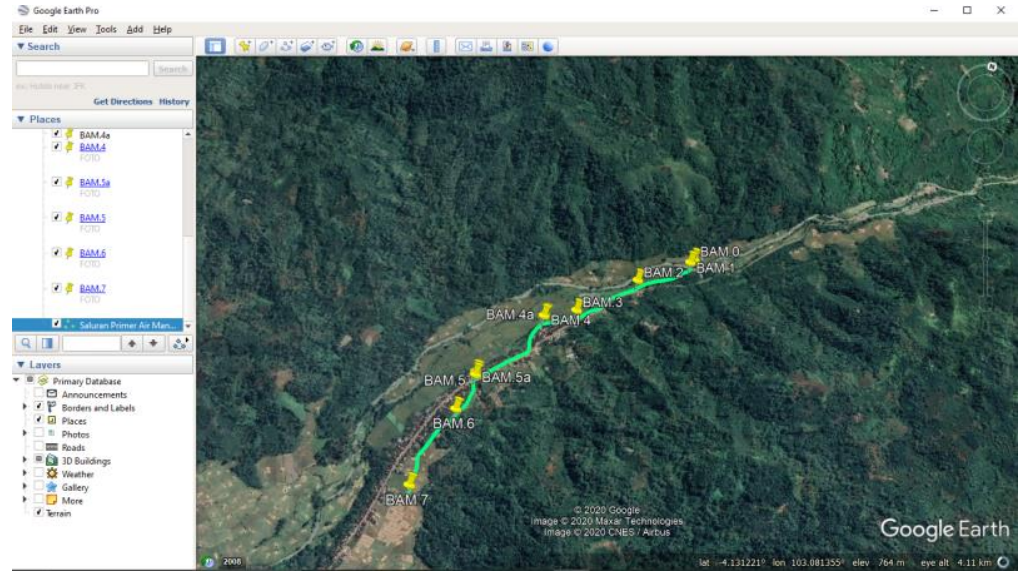

Gambar 7: Tampilan ruas yang sudah diinput deskripsi saluran 


\section{Kesimpulan}

Dari penelitian ini dapat ditarik kesimpulan bahwa berdasarkan perbandingan nilai efisiensi dan kinerja saluran primer Air Manna I diperoleh pada ruas 3 merupakan prioritas pertama untuk direhabilitasi, karena ruas saluran tersebut masih berupa tanah sepanjang $125 \mathrm{~m}$.

\section{Daftar Pustaka}

[1] Presiden RI, Peraturan Pemerintah Republik Indonesia No. 77 tahun 2021 tentang Irigasi, Jakarta: Lembaga Negara, 2001.

[2] Menteri PU, Peraturan Menteri PUPR No 14 tahun 2014 tentang Kriteria dan Penetapan Status Irigasi, Jakarta: Kementrian PU, 2014.

[3] Anonim, SNI 3408:2015 Tata Cara Pengukuran Kecepatan Aliran Pada Uji Model Hidraulik Fisik (UMH-fisik) dengan alat ukur arus tipr baling-baling, Jakarta: Lembaga Negara, 2015.

[4] B. Triadmojo, Hidraulika II, Edisi Kedua, Yogyakarta: Beta Offset, 1996.

[5] T. P. W. M. IPB, Laporan Penelitian Managemen Tipe "C" dan "D" mengenai Kehilangan Air pada Jaringan Utama dan pada Petak Tersier di DaerahIrigasi ManulubuKabupaten Kupang, Bogor, 1993.

[6] Sudjarwadi, Dasar- Dasar Teknik Irigasi, Yogyakarta: Fakultas Teknik Universitas Gajahmada, 1987.

[7] Menteri PU, Peraturan Menteri PUPR Nomor 12/PRT/M/2015 tentang Eksploitasi dan Pemeliharaan, Jakarta: Pemerintah Republik Indonesia, 2015.

[8] Menteri PU, Peraturan Menteri PU No 32 tahun2007 tentang Pedoman Operasi dan Pmeliharaan jaringan Irigasi, Jakarta: Kementerian PU, 2007.

[9] H. B. Ibrahim, Rencana dan Estimate Real of Cost, Cetakan Ke-2, Jakarta: Bumi Aksara, 1993.

[10] S. Djojowirono, management Konstruksi I, Yogyakarta: KMTS UGM, 1984. 